\title{
Relationship between body mass index with eruption of third permanent molar teeth
}

\author{
Deka SJ', Mahanta Putul', Doungel Nomi ${ }^{3}$, Bora Neelutpal ${ }^{4}$, Dutta Jahnobi ${ }^{5}$, Thakuria KD ${ }^{6}$
}

Received on March 31, 2019; editorial approval on May 4, 2019

\begin{abstract}
Objective: The aim of the study is to investigate the relationship between the nutritional status and the permanent eruption of the third molar teeth aged 13-26 years. Introduction: It is known that chronology of dental development is less variable than the bone development and the method applied for this particular period of life is a reliable indicator of age. Though eruption of teeth may be affected by dietary variation, the eruption time for teeth are fairly constant. Materials and methods: It is a cross-sectional prospective study conducted among the people aged 13-26 years through a, questionnaire over 100 participants. Results: A total of $51 \%$ male and $49 \%$ female were participated in this study. Out of 25 participants of complete third molar eruption, majority 52\% (13) participants were belonging to female. In this study, the percentage of complete third molar eruption among the participants with different Body Mass Index (BMI) categories like underweight, normal and overweight were 7, 16 and 2 respectively. Conclusion: These findings suggest a relationship between nutritional status with eruption of third permanent molars. As the complete eruption of third molar is less with underweight and obese individuals, initiatives should be undertaken for health promotion among the common people regarding oral health and healthy eating.
\end{abstract} Keywords: Height; weight; dentition; obesity; malnutrition.

\section{INTRODUCTION}

One of the greatest problems for India is undernutrition among children. Malnutrition, the condition resulting from faulty nutrition, weakens the immune system and causes significant growth and cognitive delay. Growth assessment is the measurement that best defines the health and nutritional status of children. ${ }^{1}$ A balanced diet contains all the elements is very necessary for the growth of the teeth. ${ }^{2}$ So, nutritional deficiencies can delay the process of eruption of permanent teeth. $^{3}$

On the other hand, dental development is relatively independent from another systems of maturation. ${ }^{4}$ Though eruption of teeth may be affected by dietary, climatic, racial and geographical variation, the eruption time for deciduous and permanent teeth are fairly constant. Eruption of teeth is one of the changes observed easily among the various dynamic changes that occur from formation of teeth to the final shedding of it. There is a significant time lag between cutting of a tooth into the mouth and completion of eruption of teeth. ${ }^{5}$

As it is a debatable to know whether nutritional status has any role in the process of dentition or not, this paper has aimed to know the relationship between the nutritional status with eruption of permanent third molar teeth of aged 13-26 years.

\section{MATERIALS AND METHODS}

It is was a cross-sectional prospective study conducted over 100 participants aged 13-26 years. Here, we have investigated
Address for correspondence
${ }^{1}$ Associate Professor
Email: subha.deka@gmail.com
Mobile: +919435338109
${ }^{2}$ Professor
Department of Forensic Medicine and Toxicology
Assam Medical College and Hospital, Dibrugarh, Assam, India
${ }^{3}$ Associate Professor (Corresponding Author)
Physiology, Tezpur Medical College, Tezpur, Assam, India
Email: nomidoungel@gmail.com
Mobile: +919864071754
${ }^{4}$ Registrar, ${ }^{5}$ Lecturer, Department of Dentistry, Govt. Dental
College, Dibrugarh, Assam and India
${ }^{6}$ Assistant Professor of Physiology, TMC, Tezpur, Assam 
eruption of permanent third molar teeth in relation to nutritional status along with some co-variants with the help of a predesigned and pre-tested questionnaire, anthropometric measurements and clinical examination of the participants in the year 2019 in Assam Medical College, Dibrugarh, Assam and India.

Prior to collection of the data, Human Institutional Ethical Clearance was taken which included informed consent of the participant. The data thus collected were analyzed using Microsoft Excel software.

\section{RESULTS}

A total of $51 \%$ male and $49 \%$ female were participated in this study of evaluation of permanent third molar eruption (TME) and its relationship with the nutritional status. The age and sex wise distribution of cases are shown in Table 1.

Table 1 Distribution of the study participants according to age and sex

\begin{tabular}{|c|c|c|c|c|c|c|}
\hline \multirow{2}{*}{ Age (in Years) } & \multicolumn{2}{|c|}{ Male } & \multicolumn{2}{c|}{ Female } & \multicolumn{2}{c|}{ Total } \\
\cline { 2 - 6 } & No. & $\%$ & No. & $\%$ & No. & \% \\
\hline 13 & 1 & & 3 & & 4 & 4 \\
\hline 14 & 6 & & 13 & & 19 & 19 \\
\hline 15 & 14 & & 9 & & 23 & 23 \\
\hline 16 & 5 & & 2 & & 7 & 7 \\
\hline 17 & 2 & & 1 & & 3 & 3 \\
\hline 18 & 1 & & 1 & & 2 & 2 \\
\hline 19 & 2 & & 2 & & 4 & 4 \\
\hline 20 & 2 & & 2 & & 4 & 4 \\
\hline 21 & 5 & & 5 & & 10 & 10 \\
\hline 22 & 3 & & 2 & & 5 & 5 \\
\hline 23 & 4 & & 3 & & 7 & 7 \\
\hline 24 & 2 & & 3 & & 5 & 5 \\
\hline 25 & 3 & & 1 & & 4 & 4 \\
\hline 26 & 1 & & 2 & & 3 & 3 \\
\hline Total & 51 & 51.0 & 49 & 49.0 & 100 & 100 \\
\hline
\end{tabular}

In this study, $50 \%$ cases showed no eruption where as $25 \%$ cases showed complete TME. Out of 25 cases of complete
TME, 52\% (13) cases were belong to female. TME was more $18 \%$ (18) common in lower jaw. Details are shown in Table 2.

Table 2 Status of TME in Male and Female in different quadrant of Jaw

\begin{tabular}{|c|c|c|c|c|c|c|c|}
\hline \multirow{2}{*}{$\begin{array}{c}\text { Status of } \\
\text { Eruption }\end{array}$} & \multicolumn{2}{|c|}{ Overall } & \multicolumn{2}{|c|}{ Male } & \multicolumn{2}{|c|}{ Female } & \multirow{2}{*}{ p-value } \\
\cline { 2 - 7 } & No. & Mean \pm SD & No. & Mean \pm SD & No. & Mean \pm SD & \\
\hline No Eruption & 50 & $14.62 \pm 0.88$ & 24 & $14.96 \pm 0.91$ & 26 & $14.31 \pm 0.74$ & 0.007 \\
\hline UL & 1 & ---- & 0 & ---- & 1 & ---- & ---- \\
\hline UR & 3 & $16.00 \pm 1.73$ & 3 & $16.00 \pm 1.73$ & 0 & --- & --- \\
\hline Both Upper & 0 & ---- & 0 & --- & 0 & ---- & ---- \\
\hline LL & 1 & ---- & 1 & --- & 0 & --- & --- \\
\hline LR & 2 & $17.50 \pm 3.54$ & 1 & --- & 1 & --- & 0.206 \\
\hline Both Lower & 18 & $20.72 \pm 2.49$ & 10 & $21.40 \pm 2.27$ & 8 & $19.88 \pm 2.64$ & \multirow{2}{*}{0.835} \\
\hline $\begin{array}{c}\text { Complete } \\
\text { Eruption }\end{array}$ & 25 & $22.92 \pm 1.94$ & 12 & $22.83 \pm 1.99$ & 13 & $23.00 \pm 1.96$ & \\
\hline
\end{tabular}


UL - Upper left, UR- Upper right, LL- Lower left, LRLower right

The mean age of completion of TME in male is 22.92 years and in female it is 23 years although earliest TME was at 20 years of age and that too in female and completed by 25 years in both the sexes as shown in Table 3.

Table 3 Mean age at completion of TME in Male and Female

\begin{tabular}{|l|c|c|c|c|c|c|c|}
\hline \multirow{2}{*}{ Status } & \multicolumn{2}{|c|}{ Overall } & \multicolumn{2}{c|}{ Male } & \multicolumn{2}{c|}{ Female } \\
\cline { 2 - 8 } & No. & Mean \pm SD & No. & Mean \pm SD & No. & Mean \pm SD & p-valuc \\
\hline $\begin{array}{l}\text { Incomplete } \\
\text { Eruption }\end{array}$ & 75 & $16.32 \pm 3.01$ & 15 & $16.79 \pm 3.14$ & 10 & $15.81 \pm 2.81$ & 0.156 \\
\hline $\begin{array}{l}\text { Complete } \\
\text { Eruption }\end{array}$ & 25 & $22.92 \pm 1.94$ & 12 & $22.83 \pm 1.99$ & 13 & $23.00 \pm 1.96$ & 0.835 \\
\hline
\end{tabular}

Table 4 Mean age at Eruption of permanent $3^{\text {rd }}$ molar teeth in upper and lower jaw

\begin{tabular}{|c|c|c|c|c|c|}
\hline & \multicolumn{2}{|c|}{ Upper Jaw } & \multicolumn{2}{|c|}{ Lower Jaw } & \multirow{2}{*}{ p-value } \\
\hline & No. & Mean \pm SD & No. & Mean \pm SD & \\
\hline Either Left or Right & 2 & $18.00 \pm 00$ & 2 & $19.50 \pm 0.71$ & ----- \\
\hline Both Left \& Right & 18 & $20.72 \pm 2.49$ & 0 & ----- & ----- \\
\hline
\end{tabular}

In Table 4, mean age at eruption of third molar in upper and lower jaw are shown as a comparison.

\section{DISCUSSION}

Public health issues and nutritional imbalances of the people of Assam, living in this part of the Nation still needs special attention.

Out of 100 participants of this study, 25\%(25) shows complete TME in all quadrants where female outnumbered by $52 \%(13)$, over male $48 \%(12)$. TME was more $18 \%(18)$ in both lower jaw. This finding is in strong agreement with a study carried out by Mahanta P. In his study, it was revealed that earliest TME to be in female at 16 year and completed by 24 years in both the sexes and that too in lower jaw in both the sexes. ${ }^{6,7}$

Many other studies on TME it was concluded that it erupts earliest by 16-17 years and that too in female and one year later in male and completed by 24 years in both the sexes. This findings of third molar eruption between 16-25 years are well tallied with the findings of Gorden et $\mathrm{al}^{8}$, Scot ${ }^{9}$, Polson ${ }^{10}$, Smith ${ }^{11}$, Kerr ${ }^{12}$, Grewal ${ }^{13}$, Savara and Steen ${ }^{14}$, Tedeschi et $\mathrm{al}^{15}$, Hassanali ${ }^{16}$, Hagg and Taranger ${ }^{17}$, Pathak et $\mathrm{al}^{18}, \mathrm{Rao}^{19}, \mathrm{Vij}^{20}$, Korhonen et al. ${ }^{21}$ and Chaurasia. ${ }^{22}$ Although, the female preponderance of TME and its completion time are tallied with those findings, yet it differ in earliest TME time with the present study. These discrepancies with the current study may be because of a smaller number of study participants and different geographical areas, etc.

The mean age of TME in both left and right quadrant was 20.72 years. TME is more $\mathbf{( 2 0} \%)$ in average economic group (BG Prasad's Social Class II).

In this study the percentage of complete TME among the participants with different BMI categories like underweight, normal and overweight were 7, 16 and 2 respectively. This high percentage of complete TME with the participant of normal BMI (p-value $=0.002$ ) is an agreement with a study conducted by Alhamda Syukra. ${ }^{3}$ However, incomplete TME was more $(35 \%)$ with the underweight participants signifying the needs of good nutrition for appropriate dentition, etc. Malnutrition and poor nutrition in early childhood affects tooth eruption. This finding is also supported by Eskeli $\mathrm{R}$ et al. ${ }^{23}$ 
The relation of TME with Socio-demographic variables are shown in Table 5 with BMI.

Table 5 Relation of Eruption of permanent $3^{\text {rd }}$ molar teeth with Socio-demographic variables

\begin{tabular}{|c|c|c|c|c|}
\hline \multicolumn{2}{|c|}{ Variables } & $\begin{array}{l}\text { Incomplete } \\
\text { Eruption }\end{array}$ & Complete Eruption & p-value \\
\hline \multirow{14}{*}{ Age (in years) } & $\begin{array}{lll}13 \\
\end{array}$ & 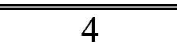 & 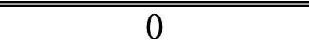 & \multirow{14}{*}{0.000} \\
\hline & 14 & 19 & 0 & \\
\hline & 15 & 23 & 0 & \\
\hline & 16 & 7 & 0 & \\
\hline & 17 & 3 & 0 & \\
\hline & 18 & 2 & 0 & \\
\hline & 19 & 4 & 0 & \\
\hline & 20 & 2 & 2 & \\
\hline & 21 & 4 & 6 & \\
\hline & 22 & 2 & 3 & \\
\hline & 23 & 2 & 5 & \\
\hline & 24 & 3 & 2 & \\
\hline & 25 & 0 & 4 & \\
\hline & 26 & 0 & 3 & \\
\hline \multirow{2}{*}{ Sex } & Male & 39 & 12 & \multirow{2}{*}{0.819} \\
\hline & Female & 36 & 13 & \\
\hline \multirow{2}{*}{ Place of Residence } & Rural & 15 & 12 & \multirow{2}{*}{0.006} \\
\hline & Urban & 60 & 13 & \\
\hline \multirow{4}{*}{ Economic Status } & $\overline{I I}$ & 10 & 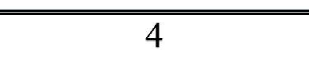 & \multirow{4}{*}{0.000} \\
\hline & II & 10 & 20 & \\
\hline & III & 23 & 1 & \\
\hline & $\overline{\mathrm{IV}}$ & 32 & $\overline{0}$ & \\
\hline \multirow{2}{*}{ History of Disease } & Yes & 0 & 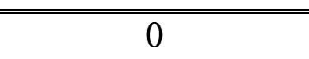 & \multirow{2}{*}{----- } \\
\hline & $\overline{\text { No }}$ & 75 & 25 & \\
\hline \multirow{3}{*}{ BMI } & Underweight & 35 & 7 & \multirow{3}{*}{0.002} \\
\hline & Normal & 31 & 16 & \\
\hline & Overweight/Obese & 9 & 2 & \\
\hline \multirow{4}{*}{ Height in $\mathrm{cm}$} & $140-150$ & 13 & 4 & \multirow{4}{*}{0.171} \\
\hline & $150-160$ & 32 & 5 & \\
\hline & $160-170$ & 23 & 12 & \\
\hline & $170-180$ & 7 & 4 & \\
\hline \multirow{3}{*}{ Weight in $\mathrm{kg}$} & $\begin{array}{l}40-60 \\
\end{array}$ & $\overline{666}$ & 16 & \multirow{3}{*}{0.015} \\
\hline & $60-80$ & 9 & 8 & \\
\hline & Above 80 & 0 & 1 & \\
\hline
\end{tabular}

and Alvarez et al., ${ }^{24}$ though a study done by Boenjamin et al. in Jakarta showed no association between nutritional status with the eruption of permanent third molar teeth. ${ }^{25}$

\section{CONCLUSION}

The present study showed a significant association between Body Mass Index with the eruption of third molars in Dibrugarh City. On comparing the eruption of third molar teeth in both the sexes, female showed an overall earlier eruption than males. Further, participant who were underweight and over weight were found to have delay in eruption of third molar teeth than participant with normal BMI. Hence, in future, longitudinal and multicentric researches are recommended with wide range of participants to determine the trends in the eruption of third molar teeth among Assamese population. 
Limitation: Number of participants should have been larger. A good number of participants is necessary to opine about TME in some variables with accuracy.

Acknowledgement: Acknowledged the needed help of Dr Hiranya Saikia, Department of Community Medicine for helping us in statistical analysis.

Conflict of interest: None declared.

Ethical clearance: Taken.

Source of funding: None declared.

Author Disclosure: (1) The article is original with the author(s) and does not infringe any copyright or violate any other right of any third party. (2) The article has not been published (whole or in part) elsewhere, and is not being considered for publication elsewhere in any form, except as provided herein. (3) All author(s) have contributed sufficiently in the article to take public responsibility for it and (4) all author(s) have reviewed the final version of the above manuscript and approved it for publication.

\section{REFERENCES}

1. Anurag Srivastava, Syed E Mahmood, Payal M Srivastava, Ved P Shrotriya, Bhushan Kumar. Nutritional status of school-age children: a scenario of urban slums in India. Arch Public Health 2012;70(1):8.

2. Department of Health Republic of Indonesia. Teeth and healthy. Health Mag 2006;170:66.

3. Situmorang N. Satisfaction survey in teeth and mouth health care at health centre, Medan. Dentika Dent J 2006:1:100.

4. Reddy V, editor. Dental anthropology- application and methods. $21^{\text {st }}$ ed. New Delhi: Inter India Publication; 1985. p. 368-9.

5. Mahanta P, Mohamed AS. A study on eruption of third molar of Libyan individual and its comparison with the Egyptian. Medico-Legal Update 2013;13(1):81-4.

6. Saini Pankaj, Pankaj Jai Prakash, Sharma Vijay Kumar, Katara Priyanka. Prevalence of eruption status of third molars in college students of Bikaner (India). Intl $\mathrm{J}$ of Medical Sci and Edu 2014 April-June;1(2):101-6.

7. Alhamda Syukra. Relationship between nutritional status and eruption of first permanent mandibular molar teeth among the school children in Indonesia. South East Asia J of Public Health 2012;2(2):85-6.

8. Schuurs DKK. Pathology of teeth. Yokyakarta: Gadjah Mada University Press Yokayakarta, 1992.

9. Eskeli R, Laine-Alava MT, Hausen H, Pahkala R. Standards for permanent tooth emergence in Finish children. Angle Orthodontist 1999;69:529-33.

10. Boenjamin, Situmorang N, Nasution L. Malnutrition. Dentika Dent J 2006;1:110.

11. Ogodescu, Emilia and Bratu, Elisabeta and Tudor, Anca and Ogodescu, Alexandru. Estimation of child's biological age based on tooth development. Rom J Leg Med 2011 June;19(2):115-24.

12. Gordon I, Turner R, Price T W. Medical Jurisprudence. $3^{\text {rd }}$ ed. Edinburgh and London: Livingstone Ltd; 1953. p. 343-72.

13. Scot DB. Dental evidences in identification and criminology. Legal med (Ed Gradwohl). $3^{\text {rd }}$ ed. Chicago USA: A John Wright and Sons Ltd. Publication; 1954. p. 452-78.

14. Polson CJ. The essential of forensic med. London: English Universities Press; Ltd; 1955. p. 51.

15. Smith S. Taylor's Principles and Practice of Medical Jurisprudence. $10^{\text {th }}$ ed. London: J and A Churchill; 1948. p. $100-1$.

16. Kerr DJA. Forensic med, a text book for students and a guide for the practioners. $6^{\text {th }}$ ed. London: Adam and Charles Black; 1957. p. 42-3.

17. Grewal RS. Medical jurisprudence and toxicology. $1^{\text {st }}$ ed. Calcutta, India: Scientific Book Agency; 1973. p. 40-1.

18. Savara BS, Steen JC. Timing and sequence of eruption of permanent teeth in a longitudinal sample of children from Oregon. J Am Dent Assoc 1978;97(2):209-14.

19. Tedeschi CG, Eckert WG, Tedeschi LG. Age determination: Forensic Medicine, a study in trauma and environmental hazards. Vol 2. Philadelphia, London, Toronto: WB. Saunders Company; 1977. p. 1124-34.

20. Hassanali J. The $3^{\text {rd }}$ permanent molar eruption in Kenyan Africans and Asians. Ann Hum Biol 1985;12(6):51723.

21. Hagg U, Taranger J. Timing of tooth emergence. A prospective longitudinal study of Swedish urban children from birth to 18 years. Swed Dent J 1986;10(5):195206.

22. Pathak SK, Mathur PN, Jain S., Saini O.P. A study of eruption of $3^{\text {rd }}$ molar in relation to estimation of age in people of thirteen to twenty-five years age group. J of Forensic Medicine and Toxicology 1999;16(1):17-9.

23. Rao N. Textbook of forensic medicine and toxicology. New Delhi, India: Jaypee Brothers Medical Publishers (P) LTD; 2000. p. 78-81.

24. Vij K. Textbook of forensic medicine and toxicology. $2^{\text {nd }}$ ed. New Delhi, India: BI Churchill Livingstone; 2002. p. 68-9.

25. Korhonen M, Larmas M. Dental age and dental health determined longitudinally from patient records in three towns in Finland. Acta Odontol Scand 2003;61(2):105-9.

26. Chaurasia BD. Human anatomy, $3^{\text {rd }}$ ed. New Delhi, India: CBS Publishers and Distributors; 1995, Vol. 1. p. 122. 
